\title{
Describing Images: A Case Study of Visual Literacy among Library and Information Science Students
}

\author{
Joan E. Beaudoin
}

This paper reports on a study that examined the development of pedagogical methods for increasing the visual literacy skills of a group of library and information science students. Through a series of three assignments, students were asked to provide descriptive information for a set of historical photographs and record reflections on their experiences via blog posts. The three separate versions of the image descriptions submitted by the students were analyzed to discern changes using descriptive statistics, and their blog posts were examined to identify recurrent themes using the constant comparative method. Findings associated with the image descriptions indicate that students' skill in describing the photographs show a modest increase across the three versions. Analysis of the blog postings revealed an overarching theme of frustration associated with the experience of developing image descriptions among the students. The underlying reasons for their frustrations are examined, and suggestions are provided for further increasing students' abilities to describe images.

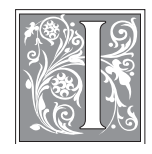

$t$ is widely acknowledged that one of the most onerous issues surrounding access to images results from the semantic gap between visual information and the printed or spoken word. ${ }^{1}$ While automatic methods can be used to provide access to textual materials, automated methods of image indexing remain problematic for all but the coarsest levels of access. As a result of this situation, humans must analyze image content and apply text-based terms to provide access to visual information. This work requires that individuals be skilled in identifying, interpreting, and describing visual information. As the number of images in the online environment continues to climb, the need for skilled individuals to describe visual materials to enable access follows a similar path. ${ }^{2}$ However, the development of visual literacy skills among graduates of programs or schools of library and information science has not kept pace with this increasing need. ${ }^{3}$ This study attempts to alleviate this situation by examining the feasibility of developing individuals' visual literacy skills through coursework in the domain of library and information science. While this study examined library and information science students, the methods described here could be applied in various disciplines to develop a greater understanding of visual materials among individuals living in a media-saturated world.

Joan E. Beaudoin is Assistant Professor in the School of Library and Information Science at Wayne State University; e-mail: joane.beaudoin@gmail.com. (C) 2016 Joan E. Beaudoin, Attribution-NonCommercial (http://creativecommons.org/licenses/by-nc/3.0/) CC BY-NC. 


\section{Literature Review}

Definitions of visual literacy generally focus on the development of several specific competencies surrounding an individual's ability to read, create, and communicate about, and through, visual content. A thorough review of the definition of visual literacy as encountered in the literature is beyond the scope of this paper, but the following publications can be consulted for detailed analyses of the various definitions that have been put forth since Debes' initial explanation of visual literacy in 1969. ${ }^{4}$ Due to the nature of the research undertaken in this study, visual literacy discussed here is limited to the ability to read: that is, to analyze, identify, and describe (communicate via text), the visual content (people, places, things, and ideas) of images.

Libraries and archives have historically been seen as bastions of textual materials, and in those institutions where visual materials were held, an uneasy relationship often existed between image- and text-based collections. This text-centered view within libraries has slowly shifted in recent years, thanks in part to the development of the web and the technological advances that have allowed for the easy exchange of digital content. In parallel with these developments has been an increased understanding of the role that visual content plays in the exchange of information and the development of knowledge. ${ }^{5}$ This modified focus among libraries and archives has led to recognition that these institutions need to 1) develop programs that support the understanding and use of visual content among their constituencies, and 2) describe the visual materials held within their collections.

Several authors working within libraries and archives have commented on what institutions should be doing to support the use of visual materials. Interestingly, the literature within the library and information science discipline has primarily examined the topic of visual literacy instruction, while those authors writing from an archival perspective have tended to focus on how to interpret and provide access to historical photographs. ${ }^{6}$

Within the library-based discussions of visual literacy, the most commonly encountered topics include instruction for searching for images, evaluating sources and images, citation methods, and copyright issues for visual content. While there is general agreement among the authors over the treatment of these topics within library-based instruction, some debate exists among the individuals responsible for developing competencies surrounding image interpretation. Nelson states that librarians should limit themselves to teaching image search and source evaluation skills, but that "using images as information sources and making sense out of them by critically analyzing their meanings... falls within the exclusive domain of the subject instructor." ${ }^{17}$ This dichotomy between the librarian's role (locating, evaluating, and citing visual materials) and that of the student-scholar-teacher (interpreting and creating visual materials) was also discussed by Harris. ${ }^{8}$ Thinking about this idea a bit further, we are likely to conclude that the critical skills for librarians to impart through visual literacy instruction may not necessarily be interpreting an image's content, but how to find information about the image through keywords, statements, and questions that can be tied together to create a rich analysis. ${ }^{9}$

In contrast to the literature concerning the topic of visual literacy within the library, authors writing from an archival perspective have largely focused their attention on how to develop visual literacy competencies for image analysis and description. Additionally, when visual literacy is discussed, it is often directed toward the archivists rather than the users that the archives serve. Kaplan, Mifflin, and Schwartz discuss how the development of visual literacy among archivists impacts access to archival materials. ${ }^{10}$ These authors note that the development of visual literacy skills among archivists helps them better understand and deal with visual materials. Kaplan and Mifflin suggest that increasing archivists' visual literacy skills would lead to "improved 
finding aids and catalog records, [which] will keep pace with anticipated expanding requirements of the research community."11 Schwartz takes this need for image analysis and description within the archives a step further when she states that the archivists must examine images' "intended function or role-be it personal, social, political, or economic - as a means of communicating a message across time and/or space and then to consider how to preserve and describe them in a way that respects, reveals, and retains their impact on human relations, power, and knowledge." ${ }^{12}$ For these authors, the best way for archivists to support their visual collections and their users is through the application of visual literacy skills and knowledge to image description.

That there is a keen need for trained individuals to provide access to images through well-developed descriptive records cannot be understated. Schwartz clearly articulates the issues that have resulted from poorly managed visual materials when she states that "[v]isual illiteracy, therefore, not just outside but more importantly within the profession, has relegated photographs to the margins of archivy."13 A lack of knowledge concerning visual materials within libraries and archives has meant that many rich image collections are functionally unknown and inaccessible.

One way to remedy the visual illiteracy that Schwartz notes is to ensure that visual literacy appears within the curricula of library and information science and archival programs. Unfortunately, visual literacy competencies are generally not a part of the formal training provided in these programs. ${ }^{14}$ The skills instead must be learned through coursework in disciplines that are more receptive to visual literacy and/or via on-the-job training. The placement of visual literacy amid the disciplinary landscape is a topic that has been discussed by several authors who suggest that its lack of coverage within the curriculum is based on the fact that it lacks a specific domain. ${ }^{15}$ As it is a topic that cuts across all boundaries, no one discipline can lay claim to its content. The issue of what should be taught also adds complexity of including visual literacy within the curriculum, as each discipline is likely to have a different visual canon (for instance art history has paintings, sculpture, and the like, while radiology has X-rays, MRIs, and such).

\section{Visual Literacy Competency Standards}

A development for expanding coverage of visual literacy within the curriculum that is interdisciplinary in nature can be found in the competencies articulated within the Association of College and Research Libraries' Visual Literacy Competency Standards for Higher Education (Standards). Visual literacy, as is discussed within the introductory statements to the Standards, is explained as "a set of abilities that enables an individual to effectively find, interpret, evaluate, use, and create images and visual media."16 Added to this list are the abilities to understand and explain the need and situate the creation and use of visual materials. These concepts are explained through a series of seven standards, each with a list of performance indicators and learning outcomes to be achieved.

The competencies included in the Standards are comprehensive, so a subset of these was selected for use in the present study to assess the development of the skills required of students to analyze and describe historical photographs. The specific standards, performance indicators, and learning outcomes examined here were limited to the items from the Standards found in table 1.

For this study, the course content was designed with the goals of increasing students' ability to evaluate existing records associated with images (Standards 4), to see and analyze the content of images (Standards 3), and to usefully communicate image content via textual descriptions (Standards 5). A related goal, found in Standards 2, was the development of students' skill in identifying terms useful to performing research about the images being examined. 


\begin{tabular}{|c|}
\hline $\begin{array}{c}\text { TABLE } 1 \\
\text { ACRL's Visual Literacy Competency Standards for Higher Education } \\
\text { Used in Study }\end{array}$ \\
\hline $\begin{array}{l}\text { Standard Two: The visually literate student finds and accesses needed images and visual } \\
\text { media effectively and efficiently. } \\
\text { Performance Indicator } 2 \text {. The visually literate student conducts effective image searches. } \\
\text { Learning Outcome: } \\
\text { d. Identifies keywords, synonyms, and related terms for the image needed, and } \\
\quad \text { maps those terms to the vocabulary used in the image source }\end{array}$ \\
\hline $\begin{array}{l}\text { Standard Three: The visually literate student interprets and analyzes the meanings of } \\
\text { images and visual media. } \\
\text { Performance Indicator } 1 \text {. The visually literate student identifies information relevant to an } \\
\text { image's meaning. } \\
\text { Learning Outcomes: } \\
\text { a. Looks carefully at an image and observes details } \\
\text { b. Reads captions, metadata, and accompanying text to learn about an image } \\
\text { c. Identifies the subject of an image } \\
\text { d. Examines the relationship of images to each other, and uses related images to } \\
\text { e. Recognizes when more information about an image is needed, develops } \\
\text { questions for further research, and conducts additional research as appropriate }\end{array}$ \\
\hline $\begin{array}{l}\text { Standard Four: The visually literate student evaluates images and their sources. } \\
\text { Performance Indicator } 3 \text {. The visually literate student evaluates textual information } \\
\text { accompanying images. } \\
\text { Learning Outcomes: } \\
\text { a. Evaluates information that accompanies images for accuracy, reliability, } \\
\text { currency, and completeness } \\
\text { b. Uses observation of visual content to evaluate textural information } \\
\text { c. Verifies image information by consulting multiple sources and conducting } \\
\text { research as necessary }\end{array}$ \\
\hline $\begin{array}{l}\text { Standard Five: The visually literate student uses images and visual media effectively. } \\
\text { Performance Indicator } 4 \text {. The visually literate student communicates effectively with and } \\
\text { about images. } \\
\text { Learning Outcome: } \\
\text { d. Includes textual information as needed to convey an image's meaning (for } \\
\text { example, using captions, referencing figures in a text, incorporating keys or } \\
\text { legends) }\end{array}$ \\
\hline
\end{tabular}

The Standards clearly indicate the specific knowledge and skills needed to become visually literate; however, the pedagogical methods for how these are to be achieved are beyond its scope. Nevertheless, there is a need for the development and testing of methods to increase students' abilities in image interpretation and description, and so the following study was undertaken.

\section{Preliminary Details of the Study}

This paper communicates the findings of a case study that examined the methods used to develop visual literacy skills among graduate students enrolled in a library and information science course. Course content and a series of exercises were created to develop the students' skills in analyzing and describing the visual content of historic photographs. As the students' own thoughts and beliefs surrounding their image 
description experiences could reveal useful information, they were asked to reflect upon the work they did in blog postings.

The images assigned to the students through the course exercises were taken from the Detroit News Collection belonging to the Walter P. Reuther Library of Labor and Urban Affairs (Reuther Library) at Wayne State University. The collection is the photographic archive of one of Detroit's longest-running newspapers, the Detroit News. The ownership of this collection of photographic materials was transferred to the Reuther Library in 1997. The photographic prints and negatives belonging to this collection date roughly to a hundred-year period between the late nineteenth and late twentieth centuries. Funding received from the Institute of Museum and Library Services allowed the Reuther Library to process a portion of roughly 800,000 photographic images in the collection and place the images online. The images in this online collection, known as the Virtual Motor City, are openly available on the web for individuals to search, view, and download. ${ }^{17}$

In preparation for the course exercises, the currently available image descriptions for a subset of photographs were gathered and copied into a spreadsheet. The descriptive information, of which there are several standard fields, and a URL to each image was included in the spreadsheets. An example image and record that students would be presented with can be seen in image 1, and an example of an accompanying descriptive record is given in table 2. The records for the Virtual Motor City collection's images vary in their levels of description, and, as is the case here, the description is sometimes a poor match to the image content. In this example, the image shows two young girls waving on a rough wooden-planked structure, whereas the record's title reads "Steamship; Tashmoo." Records with weak descriptions are the result of the newspaper's original

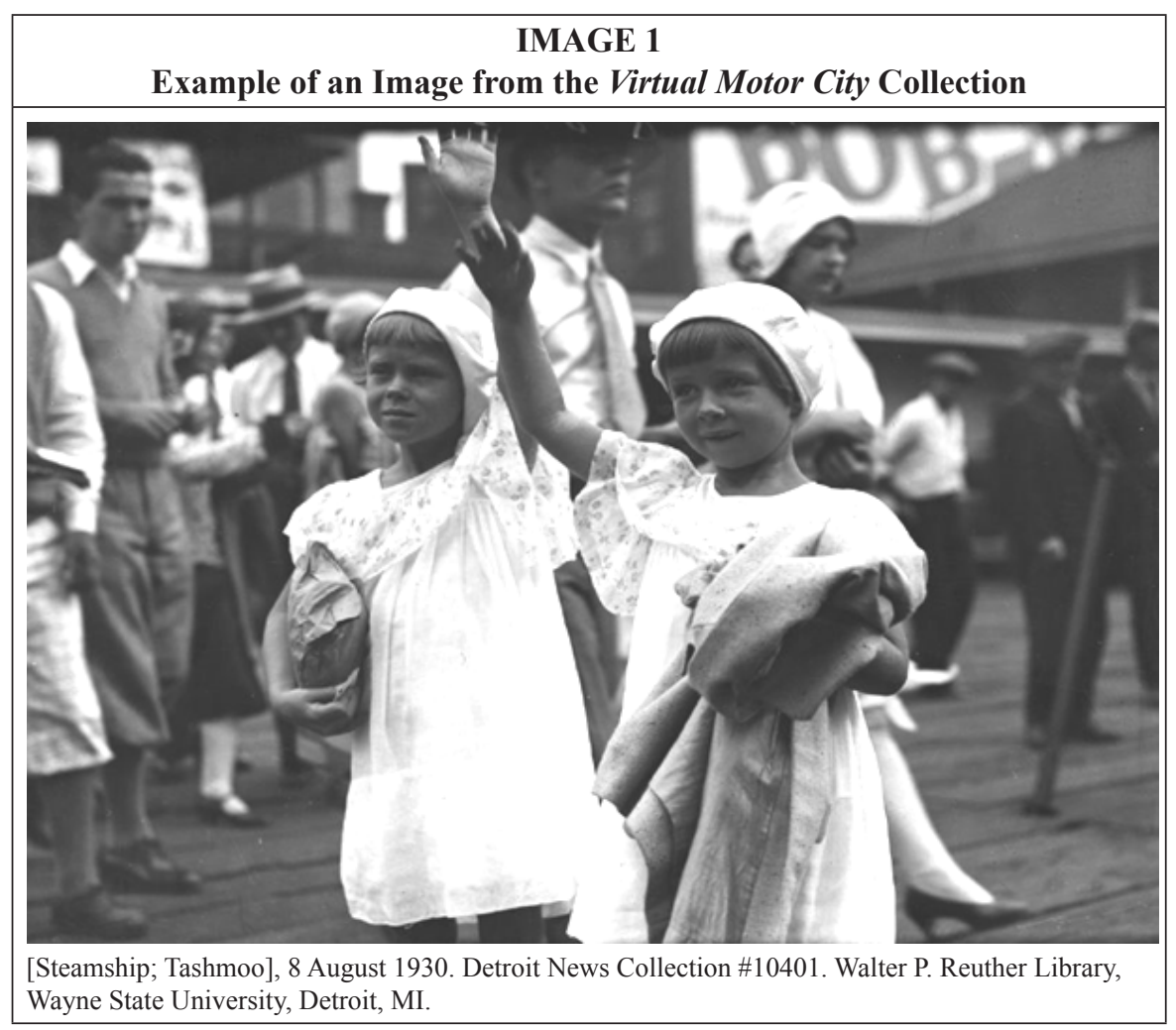




\begin{tabular}{|l|l|}
\hline \multicolumn{2}{|c|}{ TABLE 2 } \\
\hline Field Name & Field Data \\
\hline Title & Steamship; Tashmoo \\
\hline Record ID & 10401 \\
\hline Historical Title & $\begin{array}{l}\text { Steamship; Tashmoo } \\
1 \text { neg; glass }\end{array}$ \\
\hline Date & $8-8-1930$ \\
\hline Decade & 1930 s \\
\hline Film Size & $4 x 5$ \\
\hline Donor & The Detroit News \\
\hline & $\begin{array}{l}\text { C 2003 Wayne State University. All images associated with the Virtual } \\
\text { Motor City Collection are protected by United States copyright law. } \\
\text { Duplication or sale of all or part of any of the data or images is not } \\
\text { permitted without consent of the copyright holder. }\end{array}$ \\
\hline
\end{tabular}

filing structure, which grouped images together based on theme. When the Reuther Library processed the images in this collection, the labeling information on the file folder was used as the descriptive information for all of the scanned images within that particular folder. This image is likely one of a series taken for a newspaper story on the steamship Tashmoo, which ferried passengers on the Detroit River from Detroit to Port Huron, Michigan.

\section{Research Questions}

Methods of increasing individuals' abilities to analyze, evaluate, identify, and describe visual content have not been well researched, so this study sought to examine the effectiveness of learning activities designed to develop students' visual literacy competencies. The study consists of two framing elements: the first focuses on the course content presented by the instructor and the assignments completed by the students, while the second centers on the students' perceptions of their experiences. Thus the following research questions were developed to focus the research.

- RQ1: What is the impact of the course's instructional activities (lectures, readings, and exercises) on developing visual literacy skills among MLIS students in the areas of image description and analysis?

- RQ2: How do these MLIS students perceive their visual literacy learning process?

\section{Methods}

Two methods of data collection and analysis were used to examine the development of visual literacy skills among 31 students enrolled in a digital libraries course within a graduate-level program in library and information science at a large Midwestern university. Multiple prerequisites existed for enrollment in the course, and these consisted of coursework that provide an introduction to the fundamental topics of the library and information science profession. These core courses consist of an introduction to the history and the various professions within the domain of library and information science, as well as courses on reference, cataloging, management, and information technology. Within the introductory cataloging course, the students learn the basics of object description using several common tools used to perform 
cataloging tasks. These include controlled vocabularies (such as Art and Architecture Thesaurus, Thesaurus of Geographic Names, Union List of Artists Names, and Thesaurus of Graphic Materials) and subject heading lists (Library of Congress Subject Headings and Sears List of Subject Headings).

The digital libraries course was conducted asynchronously online, and instruction consisted of recorded lecture presentations with slides, audio, and video, supplemented with readings in a variety of digital library topics. Three image description exercises for this study were assigned at three separate points during the semester. These exercises, discussed below, had students enter information about a single set of assigned images in an Excel spreadsheet. These three spreadsheets were submitted via Blackboard, the course management system in use for online instruction at the university. An additional exercise was completed between the first and second image description exercises, when access to nonprint materials was covered in the course. Although data from this exercise were not examined for the current study, students were asked to discover and jointly develop a list of references useful to the task of image description. The second form of data collection examined the students' thoughts and beliefs surrounding their image description experiences. These data were recorded as students worked through the image description exercises using online blogs.

The image records that the students developed and entered into Excel spreadsheets were analyzed using descriptive statistics to reveal patterns in the changes made to the data. This included examining which kind of information was changed, which kind of descriptive information saw the most changes, and which version of the three spreadsheets saw the most changes. The quality of the image descriptions were assessed largely on their correctness, meaning did the student accurately identify the "of-ness" and/or "about-ness" of the images, were appropriate dates for the images determined and assigned, were existing spelling or typographical errors remedied, and were subject headings well formed. To prepare the data for analysis, the image descriptions from each of the three exercises for a student were copied into three separate sheets of a single spreadsheet. A fourth sheet, which contained a formula to compare the cells' contents of the previous three sheets, was used to identify the information that had been modified. The cells that were identified as being modified were then examined using case-ordered displays to determine what changes were made to the existing information in each of the three spreadsheet's states. ${ }^{18}$

The blog entries that students made in response to the image description exercises were recorded using Blackboard's blog feature. The blog entries for each of the three exercises were copied from Blackboard into three separate Word documents, and these were examined using the constant comparative method. All of the blog entries were examined to identify recurring themes that emerged from the students' discussions of their experiences. The constant comparative method, an iterative process of reading and rereading text-based data to discover themes and subthemes, was used to examine the students' reflective passages in their blog posts. The themes and subthemes were identified, gathered, and defined in a coding sheet. These were redefined and modified as new themes and subthemes emerged through multiple readings of the blog posts. To help ensure the reliability of the study's findings, the coding manual and a series of 25 sentences extracted from the blog postings were provided to three individuals. They were asked to assign each sentence to one theme or subtheme. These assignments were collected and tallied. The broad themes (for example, enjoyment or dissatisfaction) had a 97 percent overlap with the original coding, while the more granular themes (examples: time, loss, resources) saw an 84 percent agreement rate. These rates of agreement verify that the themes identified in the study were reflective of the participants' responses. 


\section{Exercises}

Three exercises were assigned at various points in the semester as a means of evaluating the students' developing knowledge of providing access to visual content through descriptive information. The first exercise was assigned at the start of the course when introductory materials were examined. Every student was provided a spreadsheet containing cursory data for 10 to 30 image records. Each image record in the spreadsheet would contain a record number, a URL to an online image, and corresponding data for a few fields associated with the image (see table 1). The fields with recorded information varied across the images. However, the most commonly found fields in the spreadsheets consisted of historical title, decade, and date. Many of the spreadsheets' cells of information were blank. The students were asked to identify what is being seen in each image, when each image was made, and the ideas being expressed through the image. They were instructed to use traditional library-oriented descriptive tools to complete the work. Students were given directions about what kinds of information should be recorded in each field, and this was accompanied by a list of potentially useful reference resources and links to various tools helpful to performing the work. ${ }^{19}$ The students also received, as a part of the assignment's instructions, examples of well-formed Library of Congress Subject Heading entries that were created for similar kinds of image content. The students were asked to add and/or modify the information for each image assigned to them, paying particular attention to developing the title, description, LC subjects, and description fields. Students were also asked to provide free text terms for each image.

Exercise 2 was assigned in week 8 when the topics of evaluation and quality control in digital libraries were examined. At this point in the course, students had been exposed to several topics useful to creating descriptive entries for images (for instance, cataloging and selecting content, and information retrieval). In exercise 2, a second student reviewed the spreadsheet that was completed in exercise 1 by another unidentified classmate. Students were asked to record any changes they felt needed to occur in the spreadsheet for exercise 2. After these changes were completed, the spreadsheet from exercise 2 was returned to the student who worked on this set of images in exercise 1. For the final exercise, students had the opportunity to work again on their spreadsheet near the end of the semester. In exercise 3, students were asked to examine their spreadsheet to ensure their final version was error free and included information missing from the earlier attempts at image description. This was the last assignment before the students' final digital projects were due at the end of the semester, and since the spreadsheet with the Virtual Motor City image descriptions was one of the items to be included in the digital project, there was an added incentive for students to complete these to the best of their abilities.

\section{Findings}

Analysis of the image descriptions and the blog entries revealed several interesting findings. Several types of descriptive information regarding the images were found to be the most often modified in the spreadsheets by the students, and the blog content showed that the students found the work involved in developing image descriptions challenging and fraught with difficulties. This section provides a detailed discussion of the findings.

Analysis of the spreadsheets showed that the students carefully followed the exercises' instructions, so the several fields of the spreadsheets that were identified as needing the most work were those that were the most frequently modified. These consisted of the fields of information concerning the title, subject headings (derived from the Library of Congress' Subject Headings list), student-developed terms, and image 
description. The changes made to the titles of the images are readily explainable, as was mentioned above, since the original titles were often not fully descriptive of the images' content. ${ }^{20}$ Although several of the original image records had Library of Congress Subject Headings applied to them, many of the records the students worked with did not. The students attempted to remedy this situation in their work; how these were developed through all three exercises is a topic we will return to shortly. A field for recording simple terms, or tags, was added to the original exported image data based on conversations with the staff at the Reuther Library. The Reuther Library's staff is interested in providing access to the images through user-applied tags, so the students' assignment of free-text terms to the images provides support for a future system development in this area. Similar to the situation with the title field, the description provided in the original records was often not reflective of the content present in the images, so the students added detail to this field to make the records more meaningful.

Several other phenomena surrounding the changes to the data were found. These consisted of the version of the spreadsheet that saw the most changes, as well as the kinds of changes that were made. In terms of which version of the spreadsheet was most often modified, it was found to be exercise 3. Approximately 60 percent of the modifications that were done to the spreadsheet descriptions were made by the original person working on exercise 3. This was an interesting finding, as exercise 2 was completed by a second person and it was thought that their view of, or knowledge about, the image content would be different and this would play out in more varied descriptions. The majority of the updates made to the spreadsheets when seen across the three exercises consisted of capitalization, punctuation, and spelling changes, an increased use of formal language/terminology, and richer descriptive detail.

The students' growing skill in identifying what they saw in the images is reflected in the descriptions they provided in the three exercises. For example, using the title field for image 1, we can trace how things changed. In exercise 1, the information about the image in the title field changed completely. The title in the original record was "Steamships; Tashmoo," and the title here was changed to "View of two girls" to better indicate the image's content. The second person working on the record in exercise 2 felt the image's connection to the Tashmoo was important to include and so modified the title provided in exercise 1 from "View of two girls" to "View of two girls on the steamship Tashmoo." The final title submitted for this image record in exercise 3 was "View of two girls waving to the steamship Tashmoo." This suggests that the original student scrutinized the image further. Through a more careful reading of the image, and a bit of research into the history of passenger boats in Detroit, the girls were perceived as standing on a pier and the description was updated in the record..$^{21}$

The Library of Congress Subject Headings assigned by the students show they were able to identify important concepts within the images, but that they struggled with the detailed mechanics of the subject heading system. An example will help illustrate this point. As seen in record 2 (shown in table 3), the original descriptive information for this image did not include any subject headings. In exercise 1 , the student provided subject headings that speak to the image's content. The subject headings identified the individuals seen in the image as provided in the historical title field and noted the fact there was a boat present. The second person working in exercise 2 recognized that the standard format of the Library of Congress Subject Headings inverts the order of names (for instance, "Gar Wood" to "Wood, Gar"). This student also developed a more specific heading for the boat. Although these headings are closer to the Library of Congress Subject Headings, they do not follow the authorized entries used in the list. As can be seen in table 4, the entries for exercise 3 repeat those given in exercise 2 . 


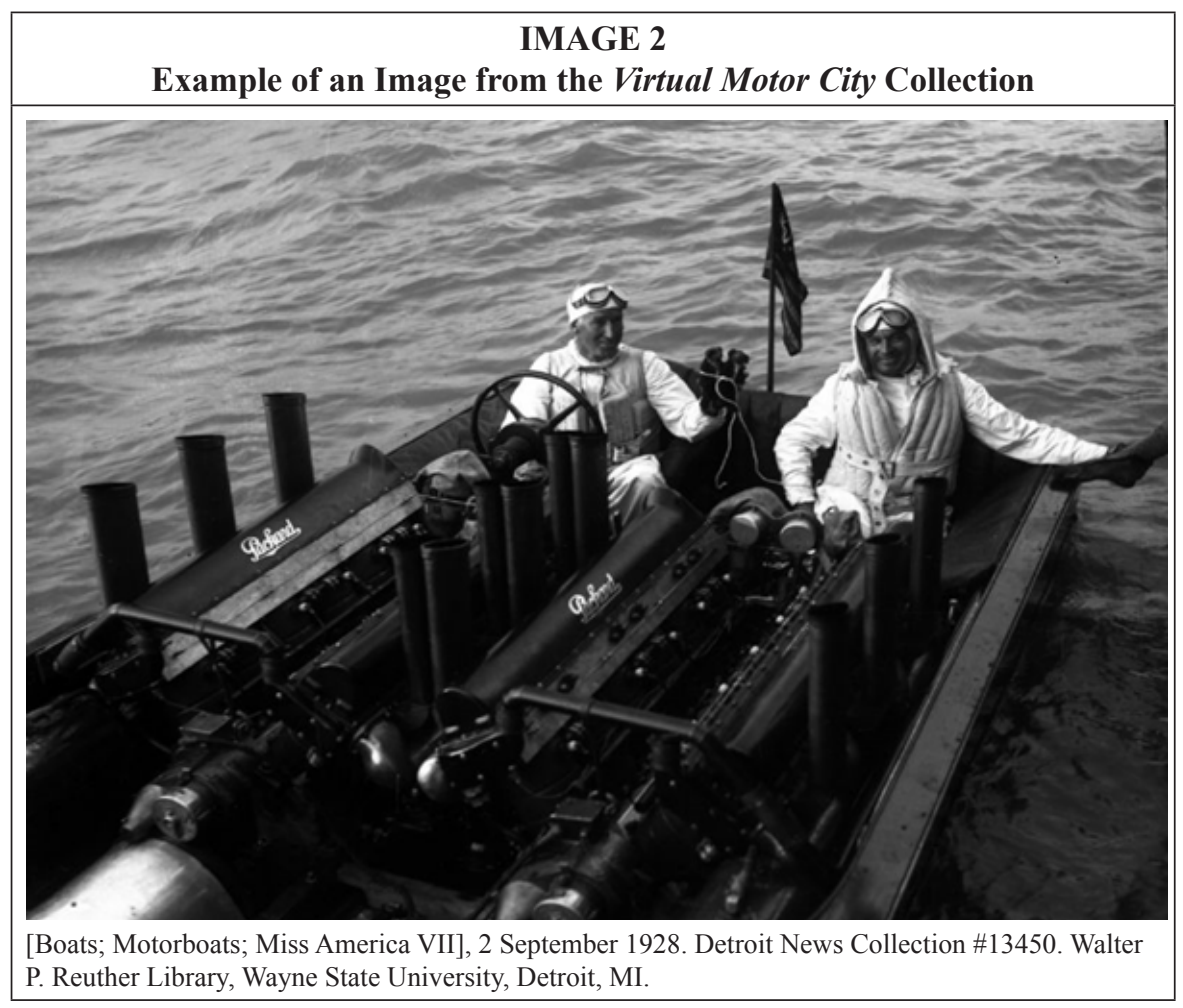

The subject headings clearly presented some unique problems for the students. Many did not search the online Library of Congress authority lists for the official names or subjects and thus many entries, while conceptually correct, did not follow the standard headings as provided by the Library of Congress. For example, the entry provided in

\begin{tabular}{|l|l|}
\multicolumn{2}{|c|}{$\begin{array}{c}\text { TABLE 3 } \\
\text { Information Provided in the Record for Image 2 }\end{array}$} \\
\hline Field Name & Field Data \\
\hline Title & Boats ; Motorboats ; Miss America VII \\
\hline Record ID & 13450 \\
\hline Historical Title & $\begin{array}{l}\text { Boats ; Motorboats ; Miss America VII } \\
\text { Head on view } \\
\text { close up of Gar Wood and Orlin Johnson }\end{array}$ \\
\hline Date & $9 / 2 / 1928$ \\
\hline Decade & 1920 s \\
\hline Film Size & 4x5 \\
\hline Donor & The Detroit News \\
\hline Rights & $\begin{array}{l}\text { C 2003 Wayne State University. All images associated with the Virtual } \\
\text { Motor City Collection are protected by United States copyright law. } \\
\text { Duplication or sale of all or part of any of the data or images is not } \\
\text { permitted without consent of the copyright holder. }\end{array}$ \\
\hline
\end{tabular}


record 2 is "Wood, Gar," which, according to the authority controlled subject heading list of the Library of Congress, should instead be "Wood, Garfield Arthur, 1880-1971." Thus, it was found that, while the students were careful to identify the content through their subject headings, they had difficulties in remedying the inconsistencies between their entries and the official form of the heading provided by the Library of Congress. This inconsistency in the assigned subject headings would negatively impact individuals' ability to find images on their chosen topic, if the headings were not altered to follow the standard entries.

\begin{tabular}{|l|l|}
\hline \multicolumn{2}{|c|}{ Variation Seen in the Subject Headings Entered for Image 2 } \\
\hline Exercise & Data \\
\hline 1 & $\begin{array}{l}\text { Gar Wood } \\
\text { Orlin Johnson } \\
\text { Boats }\end{array}$ \\
\hline 2 & $\begin{array}{l}\text { Wood, Gar } \\
\text { Johnson, Orlin } \\
\text { Miss America VII (Motorboats) }\end{array}$ \\
\hline 3 & Same as 2 \\
\hline
\end{tabular}

The students' blog entries revealed that the students felt a great sense of frustration when performing the work. This theme running throughout the blog posts could be further attributed to specific aspects that caused the students to experience frustration. When the subthemes were examined, some of these aspects were beyond their control, whereas others were those that the students could play an active role in changing. The aspects they had little or no control over were the tools and resources available to them to perform the work, the state of previously entered data, the sense of loss they experienced due to the decline or destruction of historic structures seen within the images of Detroit and the surrounding metropolitan areas, and a lack of time to research the image content in detail. Several other aspects were those that the students could potentially have a personal impact upon, and these consisted of increasing their knowledge, developing their image description skills, and being more confident in their descriptions.

Several external aspects that were discussed by the students negatively impacted their ability to provide well-developed image descriptions. The tools that were available to the students were identified as a source of frustration. In their blog postings, they often noted that they could not find the appropriate term in the Library of Congress Subject Headings list, so they were unable to apply what they felt was the best-fitting term. Many of the students found the subject heading list provided by the Library of Congress difficult to use. The students were also challenged by a lack of access and/ or availability to resources that would help them create the image records. These consisted of access to earlier issues of The Detroit News and other publications that would help them decipher the content of the images. Previous entries in the image records caused anxiety for the students, and changing descriptive information in the image records that had been entered by others was noted as being particularly difficult. The students also expressed a sense of loss associated with the historic scenes shown in the images. As they examined the images, they noted that many cultural indicators of the city (such as religious buildings, community centers, cultural events, daily life, and the like) no longer existed. Finally, the students were frustrated by the lack of time 
they had to perform the image descriptions. Most of the students noted needing more time to research the content in the images. A few students expressed frustration at their own inability to better manage their own time, however; this aspect is an example of a subtheme that straddles both external and internal forces upon a student's image description abilities.

Several aspects were discussed in the blogs that the students could act upon themselves to decrease the sense of frustration they experienced during the image description process. Increasing their knowledge about the city and its people, places, and history was an often discussed subtheme. They believed that their own lack of background knowledge concerning the history of Detroit and its environs stymied their abilities to appropriately identify the image content. A lack of practical experience in cataloging and indexing images was another subtheme students discussed that caused them difficulties. Their lack of descriptive skill meant they questioned their ability to identify the content and themes present in the images and worried about descriptive aspects such as the level of detail required. This resulted in the students' having only limited confidence in the descriptions they were able to provide for the images.

As a way to further investigate the subtheme of confidence, passages including this theme were reexamined with an eye toward describing what influenced their level of confidence. Several individuals expressed their dismay at their descriptions when they were asked to change existing data. They felt they were ill-prepared and incapable of performing the work, as this student so clearly states, "I suddenly felt very overwhelmed and under-qualified to work on this exercise.... I found myself faced with a dilemma ... am I fixing things or am I making them all horribly, horribly wrong?" [Student 25] The confidence they felt toward their work was tied to the critical nature of the descriptions they would provide. The students were acutely aware of the importance of well-described information in the successful image retrieval process. As a result, they felt a great deal of pressure to develop accurate image descriptions. This sentiment was repeated by several students. One of these took this idea a step further, pointing out the "[w]eight of knowing that your eyes might be the last ones to see an item before it goes live." [Student 9] Students were aware of the broader implications of their image descriptions. As Student 8 thoughtfully observed, "if the data is inaccurate, one might create user dissatisfaction and [give the collection] a bad reputation." Beyond creating problems in the retrieval process, poorly or incorrectly described images were seen as having a negative impact on users' interactions with a collection's and/or an institution's reputation.

As a way of trying to determine whether the students felt more confident in their image description abilities after the final exercise, their blog posts were reexamined. Two distinct patterns were discovered in their comments concerning their confidence when the blog posts associated with the three exercises were examined. For some students, the repeated attempts at developing the image records helped them feel more confident in their descriptions. Having the opportunity to step away from the descriptions for a time and then to revisit them helped to reassure them that they could review their work to correct any errors. As one student stated, "[ $t$ ]his exercise showed me the importance of coming back to materials with fresh eyes and a deeper level of experience ... I didn't find many errors, but I did feel a lot more confident in the revision process." [Student 9] Other students struggled across all of the exercises, although there was a sense that, given more time and resources, they might eventually produce something they would feel more confident about, as this student's reflection on the descriptive experience suggests: "I am not fully satisfied with my results, because I would have liked to have more time to research all of the images in order to provide more thorough annotations." [Student 13] The varied responses concern- 
ing the confidence they felt toward their descriptions is an interesting discovery that warrants additional research.

The students' blog posts also revealed what they felt they learned through the several image description exercises. Broadly speaking, the students noted they developed a greater appreciation for the work. They acknowledged the time, effort, knowledge, and experience required to perform image description well. As one student stated, "[m]y view of descriptive cataloging has changed in the sense that I now realize just how hard it is." [Student 13] While they may not have felt confident in their own abilities to perform the work, their acknowledgement of what is needed to adequately complete image description is an important finding. They can use this knowledge in the future to continue to increase their competence in this area and to understand and explain the fuller implications behind making collections of visual materials available. As individuals who may go on to direct facilities with visual collections, this is a key finding. The students also discussed developing the ability to identify instances when they do not know the answer and learning to move on when they are unable to find the answer. These realizations also suggest that this experience will help them to ultimately perform the work involved in describing images.

\section{Conclusions and Future Work}

The study set out to examine the impact of the course content on students' ability to: evaluate existing image records (Standards 4), identify and analyze the content of images (Standards 3), and effectively create descriptive records for images (Standards 5). Related to these goals was increasing students' abilities to identify terms useful to performing image research (Standards 2). The findings of the study show that the exercises increased the students' visual literacy to varying degrees across the Standards examined.

Addressing all of the Standards was the study participants' awareness of the challenges involved in describing images, and this is an important learning outcome to their professional growth and careers. Nevertheless, the development of their descriptive skills for visual materials was modest. While there was an overall pattern seen in the development of richer image descriptions, the students struggled to perform the work well. Some of their entries were incomplete or incorrect. While students modified the descriptive entries in the image records, thus suggesting they evaluated the image records (Standards 4), their ability to identify and assess the content of the images was limited (Standards 3). Whether this was an issue of limited knowledge about what was being seen in the images (Standards 3) and/or one of their limited skill in translating visual information into useful textual description (Standards $2 \mathcal{E} 5$ ) is unknown and warrants further investigation.

A means of increasing the students' descriptive abilities would be to provide intensive one-on-one guidance to their efforts as they perform the work. This could consist of reviewing their entries and then discussing these on a one-by-one basis with each student. Additional feedback to facilitate their descriptions would also be helpful in developing the students' feelings and beliefs concerning their visual literacy skills, as a lack of confidence in their own abilities was found to inhibit the descriptions they provided.

The frustration that the students experienced while working through the exercises is noteworthy and important to consider. Ravas and Stark also report on the frustration that students felt when performing image analysis. ${ }^{22}$ To encourage students to develop their descriptive abilities for visual materials, there is a need to find methods of increasing their comfort level and the satisfaction they feel in performing this work. Another way to encourage their developing visual literacy skills would be to provide students with a framework for analyzing picture content. This framework (for example: 
what is visible in the image? what is the image about? what place is shown in the image?) would help lead them through the process of identifying and analyzing visual information and encourage them to supply richer descriptions. Several authors have provided materials that could be used in developing this framework. ${ }^{23}$ Offering additional support for working with controlled vocabularies would also be useful to the description of images, as a number of students struggled with the creation of entries that were dependent on these tools. Additional studies that would extend our knowledge of image description practices could examine the rates of agreement for subject headings assigned by multiple individuals tasked with developing image records for retrieval or assess how tagging practices may impact the need for trained individuals to provide access to images among varied communities of users.

The lack of trained individuals to describe visual content is a continuing impediment to providing access to photographic and other visual collections. Additional research into developing the skills and knowledge needed by individuals to perform this work is needed. Future iterations of this study should include the suggestions made above: intensive one-on-one feedback to students' work, a framework for encouraging richer descriptions, game/competition-like rewards, and additional guidance on the tools and resources needed to develop rich descriptions. Additional data collection via interviews of students who develop the image descriptions and professionals who perform this work as a part of their day-to-day job responsibilities should also be conducted to examine in greater detail their thoughts and beliefs concerning the development of visual literacy skills. Their insights are likely to reveal aspects not discovered in the present study.

The ever-increasing quantity of online content offers a wealth of materials that were previously restricted to users operating within institutional walls. Current technologies have allowed for the easy exchange of digital content. While, in the online environment, textual items can be accessed through their word-based content, image content remains largely hidden unless manually described by individuals. Academic librarians and educators in all disciplines can integrate visual literacy instruction into their core practices to help individuals gain access to, and to better understand, visual information. This study has shown that basic image analysis, seeing the image's contents, deciphering what is being seen, and translating this visual information into descriptive text, was generally not deftly completed by graduate student participants. The skills and knowledge needed to perform this work is not inconsequential. Thus, research into methods of increasing individuals' visual literacy competence is required to move toward providing access to the rich store of visual information currently hidden from view. 


\section{Appendix: Coding Sheet}

Satisfaction: this theme relates to the enjoyment the participants experienced while performing the work required to describe the images (examples: fun, interest, excitement).

Dissatisfaction: this theme relates to the negative sentiments the participants experienced while performing the work required to describe the images (examples: frustration, boredom, unhappy).

Tools: this theme relates to the various tools the participants sought to help them perform the work required to describe the images (such as Library of Congress Subject Headings, Art and Architecture Thesaurus, Thesaurus of Graphic Materials).

Resources: this theme relates to the various publications the participants sought to help them perform the work required to describe the images (examples: The Detroit News, AIA Detroit: the American Institute of Architects Guide to Detroit Architecture, Detroit Guide).

Time: this theme relates to the time-related aspects that the participants mentioned in connection with performing the work required to describe the images (like time needed, lack of time, being rushed).

Data: this theme relates to the data present in the image records that the participants encountered while performing the work required to describe the images (such as already entered data, incorrectly entered information).

Loss: this theme relates to the destruction of buildings, cultural institutions, events, groups, and places that the participants encountered while performing the work required to describe the images (examples: demolition of churches, neighborhoods lost to corporate development, population decline).

Knowledge: this theme relates to the participants' recognition of their own limitations while performing the work required to describe the images (for instance, social and historical context, identification of people, understanding of events).

Experience: this theme relates to the participants' skill and experience in performing cataloging and image description (like development of skill, previous skill, prior work).

Courage: this theme relates to the participants' confidence in their own abilities to perform the image description (such as change in their confidence, self-assurance, risk taking).

\section{Notes}

1. Corinne Jörgensen, "Image Access, the Semantic Gap, and Social Tagging as a Paradigm Shift," 18th Annual ASIS SIG/CR Classification Research Workshop (2007), doi:10.7152/acro. v18i1.12868; Peter Enser and Christine Sandom, "Towards a Comprehensive Survey of the Semantic Gap in Visual Image Retrieval," in Image and Video Retrieval (Berlin-Heidelberg: Springer, 2003), 291-99.

2. There were over 2 billion images on Flickr alone as of November 2007. For more information, see: http://techcrunch.com/2007/11/13/2-billion-photos-on-flickr/. At the start of 2014, Flickr users were reported to upload 1 million images per day. For more information, see: http://techcrunch. com/2014/02/10/flickr-at-10-1m-photos-shared-per-day-170-increase-since-making-1tb-free/. Helena Zinkham, "Finding and Researching Photographs," in Working in the Archives: Practical Research Methods for Rhetoric and Composition, eds. A.E. Ramsey, W.B. Sharer, B. L'Eplattenier, and L. Mastrangelo (Carbondale: Southern Illinois University Press, 2009), 119-39; Joan M. Schwartz, "Negotiating the Visual Turn: New Perspectives on Images and Archives," American Archivist 67, no. 1 (2004): 107-22; James W. Marcum, "Beyond Visual Culture: The Challenge of Visual Ecology," portal: Libraries and the Academy 2, no. 2 (2002): 189-206; Joan M. Schwartz, "Coming to Terms with Photographs: Descriptive Standards, Linguistic 'Othering,' and the Margins of 
Archivy," Archivaria 1, no. 54 (2002); Elisabeth Kaplan and Jeffrey Mifflin, "'Mind and Sight': Visual Literacy and the Archivist," Archival Issues (1996): 107-27.

3. Nicole A. Beatty, "Cognitive Visual Literacy," Art Documentation 32, no. 1 (2013): 33-42; Schwartz, "Negotiating the Visual Turn," 109; Marcum, "Beyond Visual Culture," 201-03; Schwartz, "Coming to Terms with Photographs," 143-44, 160-63; Kaplan and Mifflin, "Mind and Sight," 117, 121-23.

4. Denise Hattwig, Kaila Bussert, Ann Medaille, and Joanna Burgess, “Visual Literacy Standards in Higher Education: New Opportunities for Libraries and Student Learning," portal: Libraries and the Academy 13, no. 1 (2013): 61-89; Amanda Milbourn, "A Big Picture Approach: Using Embedded Librarianship to Proactively Address the Need for Visual Literacy Instruction in Higher Education," Art Documentation 32, no. 2 (2013): 274-83; Tammy Ravas and Megan Stark, "Pulitzer-Prize-Winning Photographs and Visual Literacy at The University of Montana: A Case Study," Art Documentation 31, no. 1 (2012): 34-44; Eva Brumberger, "Visual Literacy and the Digital Native: An Examination of the Millennial Learner," Journal of Visual Literacy 30, no. 1 (2011): 19-47; Paul Conway and Ricardo Punzalan, "Fields of Vision: Toward a New Theory of Visual Literacy for Digitized Archival Photographs," Archivaria 71 (Spring 2011): 63-97; Paul Felten, "Visual Literacy," Change: The Magazine of Higher Learning 40, no. 6 (2008): 60-64; Jennifer M. Brill, Dohun Kim, and Robert Maribe Branch, "Visual Literacy Defined-The Results of a Delphi Study: Can IVLA (Operationally) Define Visual Literacy?" Journal of Visual Literacy 27, no. 1 (2007): 47-60; Ron Bleed, "Visual Literacy in Higher Education," Educause Learning Initiative 1 (2005): 1-11, available online at https://library.educause.edu/ /media/files/library/2005/1/eli4001pdf.pdf [accessed 3 April 2016]; Maria Avgerinou and John Ericson, "A Review of the Concept of Visual Literacy," British Journal of Educational Technology 28, no. 4 (1997): 280-91; John L. Debes, "The Loom of Visual Literacy-An Overview," Audiovisual Instruction 14, no. 8 (1969): 25-27.

5. Joan E. Beaudoin, "A framework of Image Use among Archaeologists, Architects, Art Historians and Artists," Journal of Documentation 70, no. 1 (2014): 119-47; Boon Chew, Jennifer A. Rode, and Abigail Sellen, "Understanding the Everyday Use of Images on the Web," in Proceedings of the 6th Nordic Conference on Human-Computer Interaction: Extending Boundaries, October 16-20, 2010, Reykjavik, Iceland, 102-11( New York: Association for Computing Machinery, 2010); Lori McCay-Peet and Elaine Toms, "Image Use within the Work Task Model: Images as Information and Illustration," Journal of the American Society for Information Science and Technology 60, no. 12 (2009): 2416-29; Cláudia Avellar Freitas and Maria Lucia Castanheira, "Talked Images: Examining the Contextualised Nature of Image Use," Pedagogies: An International Journal 2, no. 3 (2007): 151-64; Henning Müller, Christelle Despont-Gros, William Hersh, Jeffery Jensen, Christian Lovis, and Antoine Geissbuhler, "Health Care Professionals' Image Use and Search Behavior," Proceedings of Medical Informatics Europe (MIE 2006), Maastricht, Netherlands (2006): 24-32, available online at http://skynet.ohsu.edu/ hersh/mie-06-image.pdf [accessed 3 April 2016].

6. Beatty, "Cognitive Visual Literacy," 33-42; Hattwig et al., "Visual Literacy Standards in Higher Education"; Milbourn, "A Big Picture Approach"; Ravas and Stark, "Pulitzer-Prize-Winning Photographs and Visual Literacy"; Jennifer Mayer and Cheryl Goldenstein, "Academic Libraries Supporting Visual Culture: A Survey of Image Access and Use," Art Documentation 28, no. 1 (2009): 16-28; Benjamin R. Harris, "Image-Inclusive Instruction: TEACHING TIPS," College $\mathcal{E}$ Undergraduate Libraries 14, no. 2 (2007): 65-75; Benjamin R. Harris, "Visual Information Literacy via Visual Means: Three Heuristics," Reference Services Review 34, no. 2 (2006): 213-21; Loanne Snavely, "Visual Images and Information Literacy," Reference \& User Services Quarterly 45, no. 1 (2005): 27-32; Nerissa Nelson, "Visual Literacy and Library Instruction: A Critical Analysis," Education Libraries 27, no. 1 (2004): 5-10; Marcum, "Beyond Visual Culture"; Schwartz, "Negotiating the Visual Turn"; Schwartz, "Coming to Terms with Photographs"; Kaplan and Mifflin, "Mind and Sight"; Zinkham, "Finding and Researching Photographs."

7. Nelson, "Visual Literacy and Library Instruction," 8.

8. Harris, "Image-Inclusive Instruction," 66.

9. Beatty, "Cognitive Visual Literacy," 39-40.

10. Kaplan and Mifflin, "Mind and Sight," 111-13, 119-21; Schwartz, "Coming to Terms with Photographs," 155, 157-59.

11. Kaplan and Mifflin, "Mind and Sight," 107.

12. Schwartz, "Negotiating the Visual Turn," 110.

13. Schwartz, "Coming to Terms with Photographs," 144

14. Beatty, "Cognitive Visual Literacy," 34; Kaplan and Mifflin, "Mind and Sight," 117.

15. Hattwig et al., "Visual Literacy Standards in Higher Education," 62-63; Ravas and Stark, "Pulitzer-Prize-Winning Photographs and Visual Literacy," 34-35, 37; Anne Morgan Spalter and Andries Van Dam, "Digital Visual Literacy," Theory into Practice 47, no. 2 (2008): 93-101, esp. 97-98; Bleed, "Visual Literacy in Higher Education," 6; Avgerinou and Ericson, "A Review of the Concept of Visual Literacy," 282-83. 
16. Association of College and Research Libraries (ACRL) Visual Literacy Standards Task Force, Visual Literacy Competency Standards for Higher Education (2011), available online at www. ala.org/acrl/standards/visualliteracy [accessed 20 May 2014].

17. Wayne State University Digital Collections, Virtual Motor City (2014), available online at http://dlxs.lib.wayne.edu/cgi/i/image/image-idx?page=index;c=vmc [accessed on 20 May 2014].

18. Case ordered displays list all variations encountered in the data on a case-by-case basis to identify variations and patterns. For more information about this method of analysis, see Matthew B. Miles, A. Michael Huberman, and Johnny Saldaña. Qualitative Data Analysis: A Methods Sourcebook (Thousand Oaks, CA: SAGE Publications, Inc., 2013), 215-18.

19. The following is a selected list of tools and resources that students were pointed to for performing the work. The Detroit News, The Detroit Free Press, Images of America series, Arcadia Publishing, various authors and dates, ProQuest's News \& Newspaper Collection, www.proquest. com/libraries/schools/news-newspapers/; Joe T. Darden, and Richard W. Thomas, Detroit: Race Riots, Racial Conflicts, and Efforts to Bridge the Racial Divide (East Lansing, MI: MSU Press, 2013); John Walsh, "The Use of Library of Congress Subject Headings in Digital Collections," Library Review 60, no. 4 (2011): 328-43; Tomasz Neugebauer, "Image Indexing," The Indexer 28, no. 3 (2010): 98-103; Yale University, Best Practices for Descriptive Metadata (2008), available online at www. library.yale.edu/dpip/bestpractices/ [accessed 19 June 2014]; Jacki Ganendran and Lynn Farkas, Learn Library of Congress Subject Access (Friendswood, Tex.: Total Recall Publications, 2007); Karen Chittenden, Subject Indexing with TGM: A Case Study in Selecting Access Points for Photographs (2004), available online at www.loc.gov/rr/print/tp/SubjectAccessHineCaseStudy.pdf [accessed 19 June 2014]; Helena Zinkham, Subject Indexing for Pictures: An Overview (rev. 2004), available online at www.loc.gov/rr/print/tp/Subject\%20Indexing\%20for\%20Pictures.pdf [accessed 19 June 2014]; Alejandro Jaimes and Chang Shih-Fu, "A Conceptual Framework for Indexing Visual Information at Multiple Levels," ISET/SPIE Internet Imaging 3964 (2000): 1-14, available online at www. ee.columbia.edu/ln/dvmm/publications/00/ajaimes-spie00_internet.pdf [accessed 11 June 2014]; Nouvo Systems, Basic Strategies in Reading Photographs (1998), available online at http://nuovo. com/southern-images/analyses.html\#objective [accessed 18 June 2014]; Elizabeth W. Betz, Graphic Materials: Rules for Describing Original Items and Historical Collections (1982), available online at www.loc.gov/rr/print/gm/GraMatWP8.pdf [accessed 19 June 2014]; Katharine Mattingly Meyer, Detroit Architecture: A.I.A. Guide (Detroit, Mich.: Wayne State University Press, 1980); W. Hawkins Ferry, The Buildings of Detroit: A History (Detroit, Mich.: Wayne State University Press, 1968); Clarence Monroe Burton, William Stocking, and Gordon K. Miller, The City of Detroit, Michigan, 1701-1922, vol. 5 (Chicago: The SJ Clarke Publishing Company, 1922).

20. The Library of Congress Subject Headings ( $L C S H$ ) were chosen for this study since this is the authority controlled subject list in place for the Virtual Motor City collection. It was hoped that the image descriptions provided by the students could be used to update the collection's records to enhance access.

21. Indicators of the pier context are found in the rough planks beneath the girls' feet, the signage (the partially obscured Bob-Lo sign seen in the background was that of another passenger boat line in operation at the same time and place), and the throngs of people walking about.

22. Ravas and Stark, "Pulitzer-Prize-Winning Photographs and Visual Literacy," 42-43.

23. Ravas and Stark, "Pulitzer-Prize-Winning Photographs and Visual Literacy," 41-42; Lulu Rodriguez and Daniela V. Dimitrova, "The Levels of Visual Framing," Journal of Visual Literacy 30 , no. 1 (2011): 48-65; Zinkham, "Finding and Researching Photographs," 129, 131-32; Anne Bamford, The Visual Literacy White Paper (Sydney, Australia: Adobe Systems, 2003), 3-4, 6-7; Kaplan and Mifflin, "Mind and Sight," 111-14. 